\title{
Determination of Major Carotenoids in Processed Tropical Leafy Vegetables Indigenous to Africa
}

\author{
Viviane Nkonga Djuikwo ${ }^{1}$, Richard Aba Ejoh ${ }^{1,2}$, Inocent Gouado ${ }^{3}$, Carl Moses Mbofung ${ }^{1}$, \\ Sherry A. Tanumihardjo ${ }^{2}$
}

${ }^{1}$ Department of Food Science \& Nutrition, University of Ngaoundéré, Ngaoundéré, Cameroon; ${ }^{2}$ Department of Nutritional Sciences, University of Wisconsin-Madison, Madison, USA; ${ }^{3}$ Biochemistry Department, Faculty of Science, University of Douala, Cameroon. Email: ejohrab@yahoo.com

Received April 14 ${ }^{\text {th }}, 2011$; revised August $1^{\text {st }}, 2011$; accepted August $8^{\text {th }}, 2011$.

\begin{abstract}
Tropical leafy-vegetables $(n=21)$ indigenous to Cameroon, Africa, were collected, processed, and analyzed for carotenoids by HPLC. The processing techniques used were oven drying; sun-drying; squeeze-washing and boiling; and a combination of boiling in alkaline salt and squeeze-washing. Carotenoids included lutein, $\alpha$-carotene, zeaxanthin, $\beta$-cryptoxanthin, and $\beta$-carotene (all-trans, 13 -cis, and 9 -cis), which varied by species $(P<0.001)$. With the exception of P. purpureum and H. sabdarifa, lutein and $\beta$-carotene were the predominant carotenoids. In the oven dried vegetables, $\beta$-carotene was between $15 \%$ and $30 \%$ of total carotenoids and the values ranged from $7.46 \pm 0.04$ in T. indica to $39.86 \pm 2.32 \mathrm{mg} / 100 \mathrm{gDW}$ in $\mathrm{V}$. oleifera. Lutein concentrations for these leafy vegetables ranged from $11.87 \pm 0.7 \mathrm{in} \mathrm{H}$. sabdarifa to $75.0 \pm 3.6 \mathrm{mg} / 100 \mathrm{~g} \mathrm{DW}$ in $\mathrm{V}$. colorata and made up $>40 \%$ of total carotenoids. Traditional preparation and processing procedures led to significant losses of carotenoids and $\beta$-carotene was most affected during sun-drying with a maximum of $73.8 \%$ loss observed in A. acanthochiton.
\end{abstract}

Keywords: Carotenoids, Processing, Vegetables, Vitamin A Component

\section{Introduction}

Leafy vegetables have been cited as a potential source of micronutrients [1]. Many types of leafy vegetables are consumed in Africa [2]. Epidemiological studies indicate that increased intake of vegetables is associated with decreased risk of certain cancers, cardiovascular disease, cataract, macular degeneration, and other age-related diseases [3]. In addition to serving as a critical source of micronutrients, leafy vegetables are a rich source of many carotenoids $[4,5]$. More than 700 carotenoids have been identified in nature. The most commonly studied include lutein, zeaxanthin, lycopene, $\beta$-carotene, $\alpha$-carotene, and $\beta$-cryptoxanthin [6]. Besides the well-known provitamin A activity of some carotenoids [7], they also function as antioxidants and enhancers of the immune response, and as such are associated with lowered risk of developing degenerative diseases $[8,9]$.

Food-based strategies to acquire the health benefits of carotenoids and improve vitamin A intake to meet the 700 and 900 micrograms of retinol activity equivalents required per day for women and men, respectively [10] in deficient populations include identifying carotenoid-rich plants among the commonly consumed foods [7]. In low income countries about $82 \%$ of vitamin A must be obtained from a variety of carotenoids in plants [11]. Provitamin A carotenoid bioconversion in the body is estimated to be $12 \mu \mathrm{g}$ beta-carotene: $1 \mu \mathrm{g}$ vitamin A (retinol activity equivalent) with much lower values obtained when consumed with oil [12]. Improving vegetable processing and preparation that allow optimal retention of vitamin A activity $[13,14]$ is important to enable consumers and processors to choose the processing and storage conditions that favor retention of carotenoids for maximum health benefits in addition to overcoming Vitamin A malnutrition.

Traditionally, boiling, squeeze-washing, and sun-drying are practiced, and generally result in the destruction of some nutrients $[15,16]$. The composition of carotenoids in leafy vegetables markedly varies with variety and geographic conditions, as well as post-harvest handling practices. Kidmosea and others [17] reported $6630 \mu \mathrm{g}$ $\beta$-carotene/100 g fresh weight (FW) in Moringa oleifera from Taiwan, while Tee and Lim [18] reported $7500 \mu \mathrm{g} /$ $100 \mathrm{~g} \mathrm{FW}$ in the same species from Malaysia. In terms of processing, Wasantwisut and others [19] showed $89 \%$ to $90 \%$ retention of carotene with 5 minutes boiling of 
vegetables while Rahman and others [20] found similar retention rates when vegetables were oven-dried or sundried. Destruction of $\beta$-carotene and lutein has been shown to be higher when these processing methods were applied $[21,22]$. To overcome such variations, data on the composition of carotenoids in leafy vegetables grown in different geographic regions and processed differently are essential.

The purpose of this study was to identify and quantify the major carotenoids in processed and unprocessed tropical leafy vegetables indigenous to Cameroon and other parts of Africa. A reliable carotenoid database will provide information to consumers and public health workers on food sources rich in these pigments.

\section{Materials and Method}

\subsection{Chemicals}

Lutein (99\%) was a gift from Kemin Industries (Des Moines, IA, USA), $\beta$-cryptoxanthin was purchased from Carotenature (Lupsingen, Switzerland), zeaxanthin and $\beta$-carotene were purchased from GNC, Inc. (Pittsburg, PA, USA), and $\alpha$-carotene was isolated and purified from high carotene carrots. HPLC grade methanol, methyltertiary-butyl ether, acetonitrile, dichloromethane, ethanol, hexane, and ammonium acetate were purchased from Fisher Scientific
(Fair Lawn, NJ, USA), and KOH was from Mallinckrodt Baker, Inc. (Phillipsburg, NJ, USA), BHT was from ICN Biomedicals, Inc. (Aurora, OH, USA), and $\beta$-apo-8' carotenyl decanoate was synthesized as published [23].

\subsection{Sample Collection and Preparation}

From a survey carried out in Ngaoundéré, Cameroon, to determine the different leafy vegetables consumed in the region and the home-processing methods used, 21 species of leafy vegetables within this region were identified in the Botany unit of the University of Ngaoundere and divided into two based on their availability within the area (group 1 as opposed to the second group, consist of those vegetables that were found in abundance). Between $600 \mathrm{~g}$ to $2000 \mathrm{~g}$ of each of these leafy vegetables were randomly obtained from 3 different farms early in the morning, when temperatures were below $15^{\circ} \mathrm{C}$, within the region and immediately (within an hour) transported in open baskets to the Biochemistry laboratory at the University of Ngaoundéré for preparation prior to analysis. Common, local, and scientific names of the vegetables in this study are given in Table 1.

The leaves were sliced into small particles, rinsed under tap water and left $10 \mathrm{~min}$ to drain until subjected to different processing conditions based on the amount of fresh vegetable

Table 1. Common, local, scientific names, moisture and carotenoid content of leafy vegetables indigenous to Cameroon, Africa, analyzed for carotenoid profiles.

\begin{tabular}{|c|c|c|}
\hline Scientific names & Common Names & Local names \\
\hline Adansonia digitata & Baobab leaves & Bokko \\
\hline Amaranthus acanthochiton & Amaranthus & Folon \\
\hline Cassia tora Linnaeus & Coffee weed & Tasba \\
\hline Ceratotheca sesamoïdes & False sesame & Goubdou \\
\hline Corchorus olitorius & Bush okra & Lalo \\
\hline Cucurbita maxima & Pumpkin leaves & Hako Mborho \\
\hline Gnetum africanum & African jointfir & Eru \\
\hline Hibiscus cannabinus & Kenaf & Gabayidje \\
\hline Hibiscus esculentus & Okra leaves & Hako bascodje (Foufoulde) \\
\hline Hibiscus sabdarifa & Folerie (thin) & Folerie \\
\hline Hibiscus sabdarifa & Folerie (white) & Folerie \\
\hline Manihot esculenta & Cassava leaves & Hako Mbaï (Foufolde) \\
\hline Moringa oleifera & Drumstick leaves & Giligandja \\
\hline Pennisetum purpureum & Elephant grass & Tige de Sissongo \\
\hline Solanum melongena & Egg plant & Aubergine \\
\hline Solanun nigrum & Black morelle & Wulahada (foufolde) \\
\hline Talinum fruticosum $\mathrm{L}$ & Ceylon spinach & Waterleaf \\
\hline Tamarindus indica $\mathrm{L}$ & Tamarind & Djabbé \\
\hline Thalinum triangulare & Poupier droit & Adoka \\
\hline Vernonia colorata & Bitter leaf & Country bitterleaf \\
\hline Vigna unguiculata & Cowpea leaves & Niebe, korky beans \\
\hline
\end{tabular}


processing conditions based on the amount of fresh vegetable available from the farms i.e., those found in larger quantities $(1800 \mathrm{~g}-2000 \mathrm{~g})$ within the region were subjected to four processing methods while those with lower quantities were only subjected to two methods. Five species were placed in the first group and were each divided into 4 lots. One was left (unprocessed) to dry at $45^{\circ} \mathrm{C}$ in an electric oven for 24 hours while the others were subjected to the following: 1) sun-drying, 2) squeeze-washing and boiling, or 3) a combination of boiling in kanwa (a local alkaline salt obtained from the Ngaoun-déré market) and squeeze-washing. For the latter, 450-g portions of fresh samples were boiled in $1 \mathrm{~L}$ water containing $10 \mathrm{~g}$ kanwa for 10 minutes before squeeze- washing and rinsing. Squeeze-washing and rinsing is a traditional process which involves crushing the vegetable with the hands and squeezing out the water and foam. This is followed by rinsing with fresh clean tap water and squeezing out the water. Data from the survey mentioned earlier were used to determine the traditional concentration of kanwa used in the preparation. The second group of leafy vegetables species were sundried and compared with the unprocessed samples that were ovendried. Sundrying involved spreading the leaves on a light cloth and exposure directly to intense tropical sunlight $\left(30^{\circ} \mathrm{C}-40^{\circ} \mathrm{C}\right)$, which was $10 \mathrm{hrs}$ daily for two days when the leaves appeared completely dried. The dried samples were stored at $-2^{\circ} \mathrm{C}$ in airtight containers for a few days then transported to Madison, Wisconsin where they were kept in similar conditions before being ground to powder and assayed. Extraction and HPLC analyses of the carotenoids were carried out in the Department of Nutritional Sciences, University of Wisconsin-Madison, Madison, WI, USA.

\subsection{Extraction and HPLC Analysis}

A modification of the procedure described by Howe and Tanumihardjo [24] was adopted for quantification of carotenoids. Carotenoids were released from dried, powdered vegetables $(0.6 \mathrm{~g})$ by heating at $85^{\circ} \mathrm{C}$ for $5 \mathrm{~min}$ in ethanol with BHT $(0.1 \%, w / v)$ followed by saponification with $400 \mu \mathrm{L} \mathrm{KOH}(80 \%$ in water). The suspension was mixed by vortex for $20 \mathrm{~s}$ and placed in a water bath $\left(85^{\circ} \mathrm{C}\right)$ for $10 \mathrm{~min}$. The reaction was halted by placing in ice and mixing with $3 \mathrm{~mL}$ deionized water. $\beta$-Apo-8'carotenyl decanoate was added post-saponification to account for mechanical losses. The mixture was extracted 4 times with hexanes to ensure complete extraction of the xanthophylls and carotenes. The combined extracts were dried under argon, reconstituted in $1 \mathrm{~mL}$ 50:50 methanol:dichloroethane and $25 \mu \mathrm{L}$ was injected onto a Waters HPLC system [C30 YMC ${ }^{\mathrm{TM}}$ carotenoid column (4.6 X $250 \mathrm{~mm}, 3 \mu \mathrm{m}), 1525$ binary HPLC pump, 717 plus autosampler, and a 996 photodiode array detector; (Milford, MA, USA)]. The HPLC solvent gradient was: solvent $\mathrm{A}$, methanol: water $(92: 8, \mathrm{v} / \mathrm{v})$ with $10 \mathrm{mmol} / \mathrm{L}$ ammonium acetate and solvent $\mathrm{B}$ was $100 \%$ methyltertiary-butyl ether. Samples were analyzed at $1 \mathrm{~mL} / \mathrm{min}$ starting with $70 \%$ solvent $\mathrm{A}$ and transitioning to $40 \%$ solvent A within $30 \mathrm{~min}$.

Lutein (Kemin Industries; Des Moines, IA, USA), $\beta$ cryptoxanthin (Carotenature, Lupsingen, Switzerland), zeaxanthin (GNC Inc., Pittsburg, PA, USA), $\beta$-carotene (GNC Inc., Pittsburg, PA, USA), and $\alpha$-carotene (purified from high carotene carrots) were identified and quantified using HPLC-purified standards. $\beta$-Carotene quantification included all-trans, 13-cis, and 9-cis isomers. Concentrations of standards were determined spectrophotometrically using their respective extinction coefficients $\left[E_{1 \mathrm{~cm}}^{1 \%}: 2592\right.$ for $\beta$-carotene, 2800 for $\alpha$-carotene, 2550 for lutein, 2386 for $\beta$-cryptoxanthin, and 2348 for zeaxanthin] [25]. Peak identification of all carotenoids was performed by comparing the retention times and absorption spectra with those of the standards. Chromatograms were generated at $450 \mathrm{~nm}$. Certain precautions were taken to avoid losses of carotenoids and other errors during analysis, such as working under gold fluorescent lights, finishing the analysis within the shortest possible time, and cooling the saponified samples before introduction of internal standards.

The validity of this method was verified with regard to accuracy, linearity and precision. The accuracy was verified by addition of specific amounts of $\beta$-Apo-8-carotenyl decanoate to a standard vegetable extract and the percentage losses used to adjust possible losses during analysis. To verify the repeatability, the same vegetable was analyzed three times and the mean and deviation presened and comparison done at $\mathrm{P}<0.05$ levels. To determine the reproducibility of the extraction, a sample was extracted three to five times to ensure complete extraction.

\subsection{Calculation of Vitamin A Activity}

Vitamin A activity, was calculated based on the in vivo conversion factor proposed by WHO where 1 RE corresponds to $6 \mu \mathrm{g}$ of $\beta$-carotene and $12 \mu \mathrm{g}$ of $\alpha$-carotene [26], [27] and results expressed in mg per $100 \mathrm{gDW}$. Vitamin $\mathrm{A}$ activity of 13 cis- $\beta$-carotene and 9 -cis $\beta$-carotene was calculated on the same strength as $\beta$-carotene.

\subsection{Statistical Analysis}

Statistical Analysis System software (SAS Institute Inc., Version 8.2, Cary, NC, USA; 2001) was used for data analyses. Processed and unprocessed samples were compared using ANOVA. When the main effect was signifycant, differences between treatments were determined using Fisher's Least Significant Difference (LDS) test. $\mathrm{P}<0.05$ was considered significant.

\section{Results and Discussion}

\subsection{Carotenoid Contents}

The carotenoids identified in the leafy vegetables were lutein, $\alpha$-carotene, zeaxanthin, $\beta$-cryptoxanthin, and all- 
trans-, 13-cis-, and 9-cis- $\beta$-carotene (Figures 1(a)-(d)). The chromatographic profiles of the carotenoids of the high and moderate carotenoid vegetable groups were almost identical. The major differences among the vegetables appeared to be the levels at which the various carotenoids were present. The predominant carotenoid in all of the vegetables analyzed except $H$. sabdarifa was lutein that appeared at about 9 minutes. $\beta$-Carotene which appeared at 25 minutes, was the second most abundant, which included some 13-cis and 9-cis isomers that appeared at 22 and 27 minutes, respectively, in most of the vegetables. The exceptions were $P$. purpureum and $H$. sabdarifa, vegetables classified in the low carotenoid group, which had different relative carotenoid profiles. Lutein predominated in $P$. purpureum which is not a dark green leafy vegetable and $\beta$-carotene predominated in $H$. sabdarifa (Figures 1(c)-(d)), which supports previously published data on carotenoids in leafy vegetables [28].

The mean carotenoid concentrations of the unprocessed and processed high carotenoid leafy vegetables are presented in Table 2, while those of the moderate and low carotenoid leafy vegetables are presented in Table 3. Except for $P$. purpureum and $H$. sabdarifa, which were low carotenoid vegetables, all leafy vegetables analyzed appeared to be good sources of carotenoids, although their contents varied among species for the unprocessed samples $(\mathrm{P}<0.001)$.

\section{2. $\alpha$ - and $\beta$-Carotene Concentrations}

In these oven-dried vegetables, $\beta$-carotene made up between 15 and $30 \%$ of total carotenoids and the values ranged from $14.67 \pm 1.48$ in C. maxima to $39.86 \pm 2.32 \mathrm{mg} / 100$ g DW in M. oleifera (Table 2) for group 1 vegetables and between $7.46 \pm 0.04$ in $T$. indica to $23.89 \pm 0.20 \mathrm{mg} / 100$ $\mathrm{g}$ DW in S. melongena for the other vegetables (Table 3). $P$. purpureum and $H$. sabdarifa (thin) had lower values for all carotenoids analyzed. Because there are such high concentrations of $\beta$-carotene in most of these leafy vegetables, they could potentially be used to help zalleviate deficiencies in vitamin A, which are prominent in most developing countries. Low levels of $\alpha$-carotene were found in the vegetables, which may be related to the "channeled" conversion of $\alpha$-carotene to lutein in the biosynthetic pathway through hydroxylase enzymes [29].

\subsection{Lutein, Zeaxanthin and $\beta$-Cryptoxanthin Concentrations}

Lutein values ranged from $33.1 \pm 4.8$ in $H$. canibalus to $75.0 \pm 3.6 \mathrm{mg} / 100 \mathrm{~g} \mathrm{DW}$ in $V$. colorata for the high carotenoid vegetables (Table 2) and between $1.8 \pm 0.7$ in $H$. sabdarifa and $49.9 \pm 2.9 \mathrm{mg} / 100 \mathrm{~g} \mathrm{DW}$ in $S$. melongena for the moderate carotenoid vegetables (Table 3). Lutein was attributable to $>40 \%$ of total carotenoids except $P$. purpureum and $H$. sabdarifa, which contained 37 and

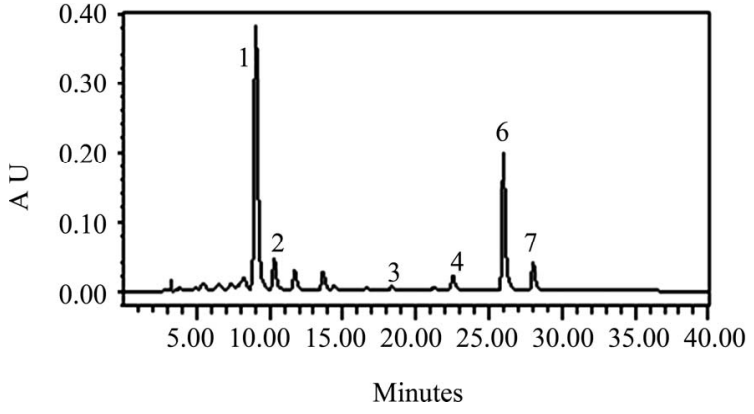

(a)

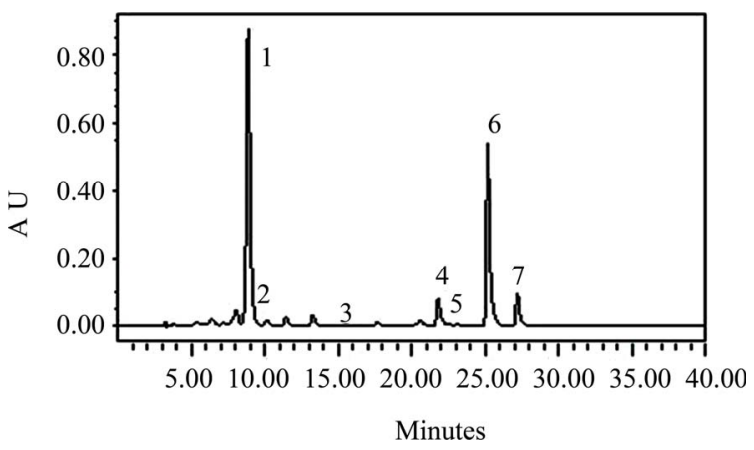

(b)

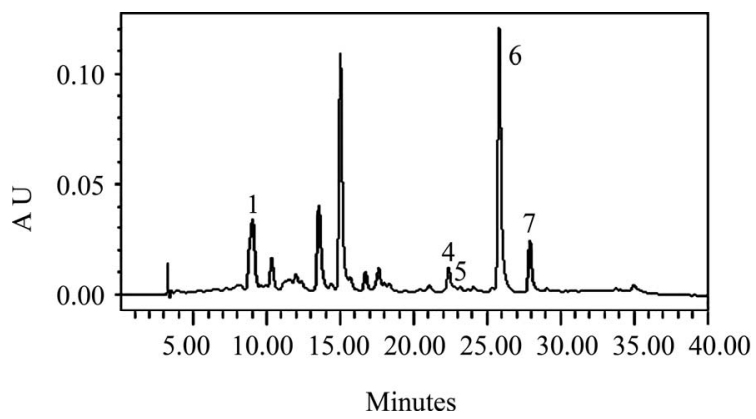

(c)

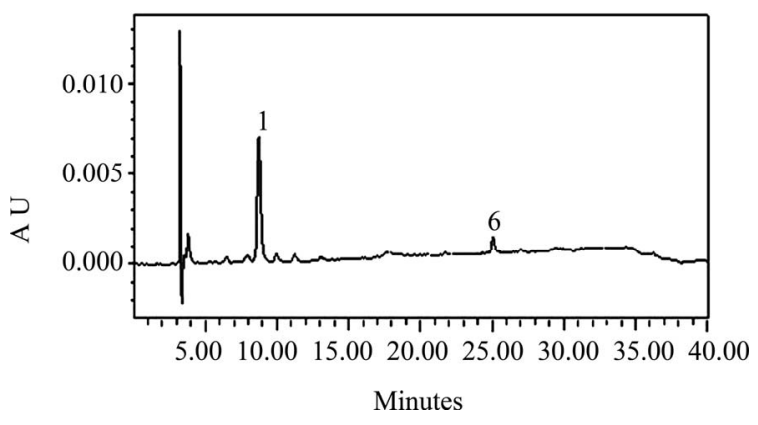

(d)

Figure 1. Typical HPLC chromatograms of the carotenoids in (a) S. melongena, (b) V. colorata, (c) H. sabdarifa-white, and (d) $P$. purpureum. These chromatograms represent the range present in indigenous green leafy vegetables from Africa [note differences in Absorbance Unit (AU) axes]. Peak identification: (1) lutein, (2) zeaxanthin, (3) $\beta$-cryptoxanthin, (4) 13-cis- $\beta$-carotene, (5) $\alpha$-carotene, (6) all-trans- $\beta$-carotene, (7) 9-cis- $\beta$-carotene. Absorbance at $450 \mathrm{~nm}$. 
Table 2. Effects of processing on the carotenoid content of tropical leafy vegetables indigenous to Cameroon and common in all of tropical Africa (mg/ $100 \mathrm{~g}$ dry weight).

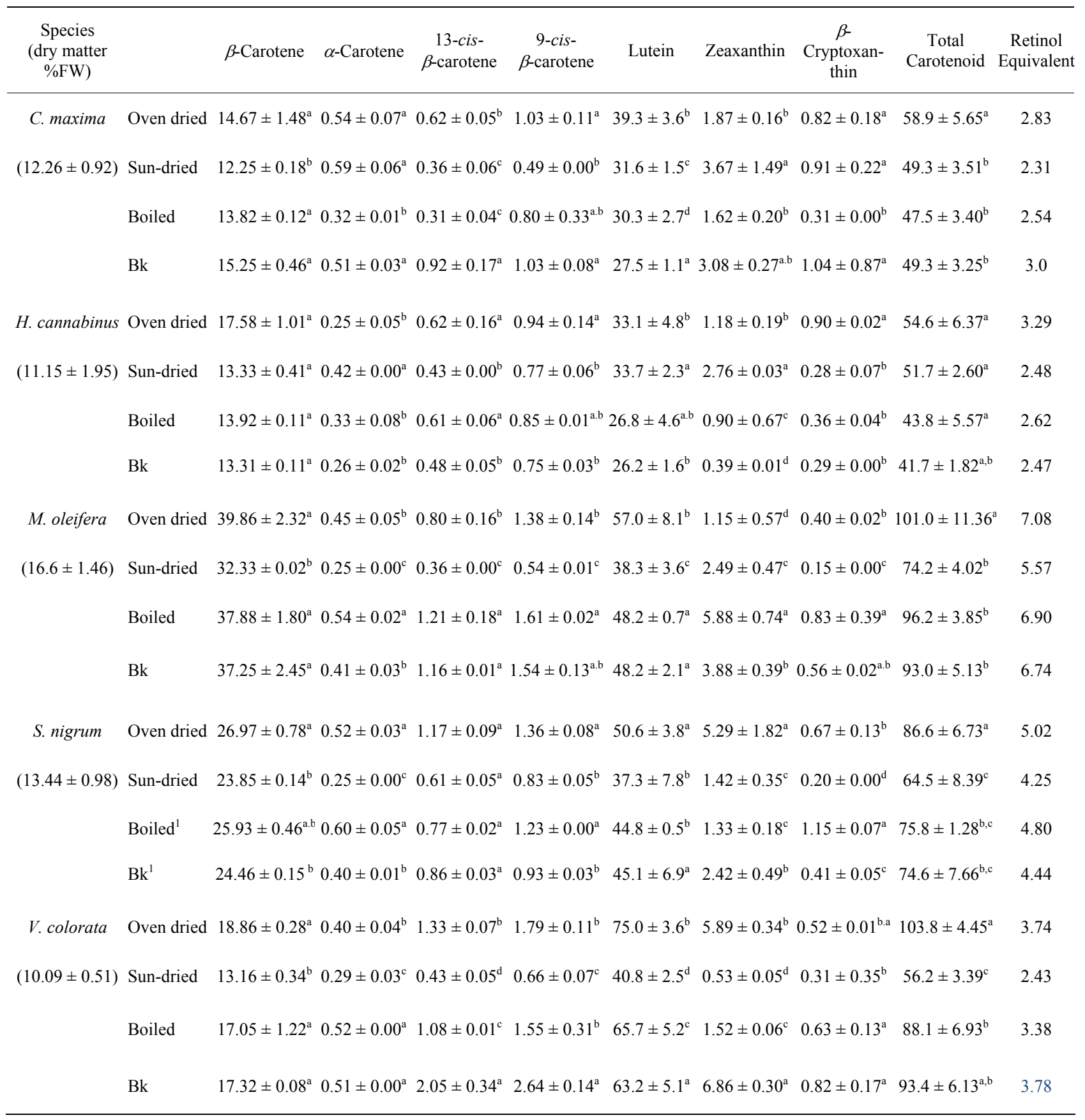

${ }^{1}$ Boiled. boiled and squeeze-washed; Bk. boiled in kanwa and squeeze-washed; ${ }^{2}$ Data are presented as means of triplicate analyses \pm SD. Means with the same superscript letter in the same column for a single vegetable are not different at $\mathrm{P}>0.05$. FW. fresh weight.

Table 3. The effects of sun-drying on the carotenoid profiles of green leafy vegetables common in Africa (mg/100 g dry weight) ${ }^{1}$.

\begin{tabular}{c}
$\begin{array}{c}\text { Species } \\
\left(\begin{array}{c}\text { Dry matter } \\
\% \mathrm{FW})\end{array}\right.\end{array}$ \\
\hline
\end{tabular}

A.acanthochitonOven dried $20.40 \pm 0.17^{\mathrm{a}} 0.25 \pm 0.01^{\mathrm{b}} 0.58 \pm 0.07^{\mathrm{a}} 0.66 \pm 0.03^{\mathrm{a}} 23.4 \pm 9.4^{\mathrm{a}} \quad 1.00 \pm 0.18^{\mathrm{b}} \quad 0.57 \pm 0.19^{\mathrm{a}} \quad 46.9 \pm 1.70^{\mathrm{a}} \quad 3.68$ 


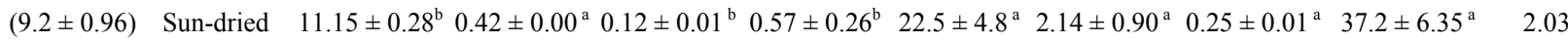

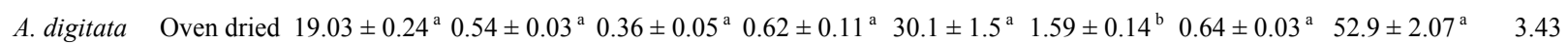

$(12.21 \pm 1.13)$ Sun-dried $12.58 \pm 0.95^{\mathrm{b}} 0.44 \pm 0.02^{\mathrm{b}} 0.25 \pm 0.05^{\mathrm{b}} 0.45 \pm 0.05^{\mathrm{b}} 26.4 \pm 1.3^{\mathrm{b}} \quad 4.08 \pm 0.30^{\mathrm{a}} \quad 0.88 \pm 0.12^{\mathrm{a}} \quad 45.1 \pm 2.79^{\mathrm{b}} \quad 2.32$

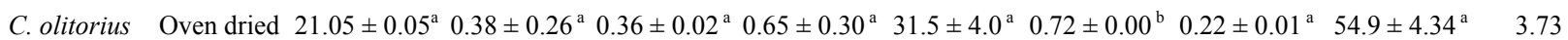

$(18.66 \pm 2.41)$ Sun-dried $\quad 11.44 \pm 0.42^{\mathrm{b}} 0.21 \pm 0.03^{\mathrm{b}} 0.22 \pm 0.02^{\mathrm{b}} 0.34 \pm 0.05^{\mathrm{b}} \quad 26.1 \pm 2.4^{\mathrm{a}} \quad 7.26 \pm 1.02^{\mathrm{a}} \quad 0.43 \pm 0.00^{\mathrm{a}} \quad 46.0 \pm 3.94^{\mathrm{a}} \quad 2.05$

C. sesamoïdes Oven dried $18.37 \pm 0.58^{\mathrm{a}} \quad 0.22 \pm 0.02^{\mathrm{a}} \quad 0.48 \pm 0.02^{\mathrm{a}} \quad 0.40 \pm 0.14^{\mathrm{a}} \quad 31.0 \pm 2.1^{\mathrm{a}} \quad 1.81 \pm 0.72^{\mathrm{b}} \quad 0.18 \pm 0.01^{\mathrm{a}} \quad 52.5 \pm 3.59^{\mathrm{a}} \quad 3.24$

$(11.84 \pm 0.87)$ Sun-dried $\quad 13.02 \pm 0.55^{\mathrm{b}} 0.21 \pm 0.05^{\mathrm{a}} \quad 0.45 \pm 0.01^{\mathrm{a}} \quad 0.53 \pm 0.09^{\mathrm{a}} \quad 27.2 \pm 4.5^{\mathrm{a}} \quad 3.12 \pm 0.40^{\mathrm{a}} \quad 0.21 \pm 0.03^{\mathrm{a}} \quad 44.7 \pm 5.63^{\mathrm{a}} \quad 2.37$

C. tora $\mathrm{L} \quad$ Oven dried $21.50 \pm 0.20^{\mathrm{a}} 0.47 \pm 0.05^{\mathrm{a}} 0.57 \pm 0.02^{\mathrm{a}} 0.98 \pm 0.06^{\mathrm{a}} \quad 36.8 \pm 2.9^{\mathrm{a}} \quad 2.53 \pm 0.25^{\mathrm{b}} 0.41 \pm 0.05^{\mathrm{a}} \quad 63.3 \pm 3.53^{\mathrm{a}} \quad 3.92$

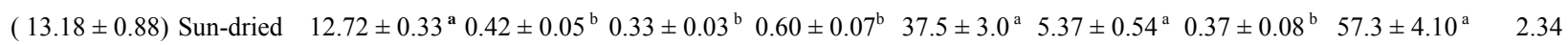

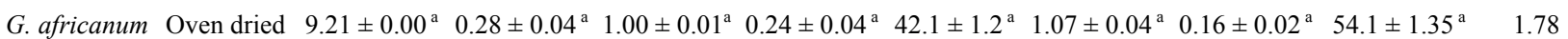

$(17.63 \pm 1.72)$ Sun-dried $2.44 \pm 0.06^{\mathrm{b}} 0.15 \pm 0.01^{\mathrm{b}} 0.77 \pm 0.13^{\mathrm{a}} 0.18 \pm 0.05^{\mathrm{b}} 29.4 \pm 1.9^{\mathrm{b}} \quad 0.06 \pm 0.03^{\mathrm{b}} \quad 0.15 \pm 0.03^{\mathrm{a}} \quad 33.2 \pm 2.21^{\mathrm{b}} \quad 0.59$

H. esculentus Oven dried $21.21 \pm 0.34^{\mathrm{a}} 0.52 \pm 0.00^{\mathrm{a}} \quad 0.53 \pm 0.06^{\mathrm{a}} \quad 0.51 \pm 0.02^{\mathrm{a}} \quad 28.1 \pm 0.9^{\mathrm{a}} \quad 2.43 \pm 0.10^{\mathrm{a}} \quad 0.35 \pm 0.02^{\mathrm{a}} \quad 53.7 \pm 1.44^{\mathrm{a}} \quad 3.78$

$(10.11 \pm 0.63)$ Sun-dried $12.45 \pm 0.16^{\mathrm{b}} 0.34 \pm 0.02^{\mathrm{b}} 0.37 \pm 0.01^{\mathrm{b}} 0.41 \pm 0.01^{\mathrm{b}} 24.4 \pm 1.5^{\mathrm{b}} \quad 1.65 \pm 0.02^{\mathrm{a}} 0.23 \pm 0.01^{\mathrm{a}} \quad 39.9 \pm 1.53^{\mathrm{b}} \quad 2.25$

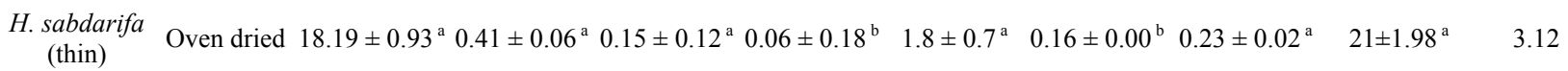

$(12.46 \pm 0.48)$ Sun-dried $\quad 11.06 \pm 1.31^{\mathrm{b}} 0.39 \pm 0.08^{\mathrm{b}} \quad 0.15 \pm 0.17^{\mathrm{a}} \quad 0.41 \pm 0.28^{\mathrm{a}} \quad 1.8 \pm 0.1^{\mathrm{a}} \quad 0.44 \pm 0.29^{\mathrm{a}} \quad 0.26 \pm 0.40^{\mathrm{a}} \quad 14.5 \pm 2.54^{\mathrm{b}} \quad 1.99$

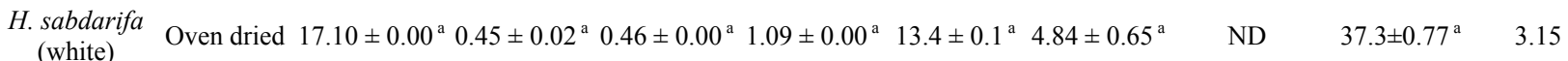

$(13.99 \pm 1.33)$ Sun-dried $13.83 \pm 0.29^{\mathrm{b}} 0.24 \pm 0.01^{\mathrm{b}} 0.26 \pm 0.01^{\mathrm{b}} 0.66 \pm 0.14^{\mathrm{a}} 12.0 \pm 1.5^{\mathrm{a}} \quad 2.59 \pm 0.14^{\mathrm{b}} \quad$ ND $\quad 28.9 \pm 2.09^{\mathrm{b}} \quad 2.48$

M. esculenta Oven dried $17.97 \pm 0.53^{\mathrm{a}} 0.28 \pm 0.02^{\mathrm{a}} 0.71 \pm 0.09^{\mathrm{a}} 0.67 \pm 0.09^{\mathrm{b}} \quad 40.4 \pm 3.7^{\mathrm{a}} \quad 3.13 \pm 0.05^{\mathrm{b}} 0.27 \pm 0.03^{\mathrm{a}} \quad 64.0 \pm 4.5^{\mathrm{a}} \quad 3.27$

$(17.29 \pm 1.63)$ Sun-dried $12.91 \pm 0.29^{\mathrm{b}} 0.27 \pm 0.01^{\mathrm{a}} 0.40 \pm 0.09^{\mathrm{b}} 0.77 \pm 0.09^{\mathrm{a}} 24.2 \pm 1.9^{\mathrm{b}} \quad 8.14 \pm 0.72^{\mathrm{a}} 0.26 \pm 0.02^{\mathrm{a}} \quad 47.0 \pm 3.93^{\mathrm{b}} \quad 2.390833$

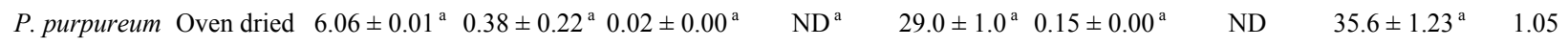

$(10.72 \pm 0.95)$ Sun-dried $\quad 4.02 \pm 0.00^{\mathrm{b}} \quad 0.28 \pm 0.0^{\mathrm{b}} \quad \mathrm{ND}^{\mathrm{b}} \quad \mathrm{ND}^{\mathrm{a}} \quad 14.1 \pm 1.1^{\mathrm{b}} \quad \mathrm{ND}^{\mathrm{b}} \quad \mathrm{ND} \quad 18.4 \pm 1.1^{\mathrm{b}} \quad 0.69$

S. melongena Oven dried $23.89 \pm 0.26^{\mathrm{a}} \quad 0.55 \pm 0.02^{\mathrm{a}} \quad 0.88 \pm 0.00^{\mathrm{a}} \quad 1.48 \pm 0.04^{\mathrm{a}} \quad 49.9 \pm 2.9^{\mathrm{a}} \quad 0.95 \pm 0.03^{\mathrm{b}} \quad 0.83 \pm 0.03 \quad 78.5 \pm 3.28^{\mathrm{a}} \quad 4.49$

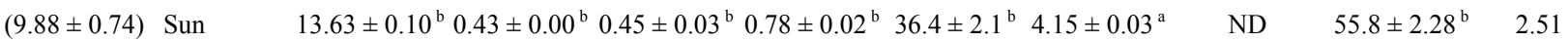

T. fruticosum Oven dried $19.47 \pm 0.61^{\mathrm{a}} 0.34 \pm 0.11^{\mathrm{a}} 0.38 \pm 0.30^{\mathrm{a}} 0.71 \pm 0.19^{\mathrm{a}} \quad 33.6 \pm 6.6^{\mathrm{a}} \quad 0.46 \pm 0.31^{\mathrm{a}} 0.18 \pm 0.00^{\mathrm{a}} \quad 55.1 \pm 8.12^{\mathrm{a}} \quad 3.47$

$(10.62 \pm 1.13)$ Sun-dried $12.52 \pm 0.19^{\mathrm{b}} 0.17 \pm 0.03^{\mathrm{b}} 0.17 \pm 0.02^{\mathrm{b}} 0.48 \pm 0.04^{\mathrm{b}} 26.8 \pm 1.2^{\mathrm{a}} \quad 0.23 \pm 0.05^{\mathrm{b}} 0.11 \pm 0.02^{\mathrm{a}} \quad 40.5 \pm 1.52^{\mathrm{b}} \quad 2.22$

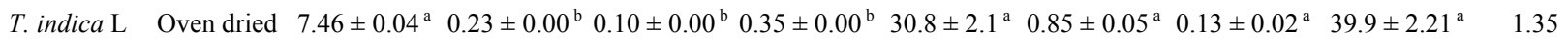

$(11.78 \pm 0.55)$ Sun-dried $1.14 \pm 0.01^{\mathrm{b}} 0.38 \pm 0.14^{\mathrm{a}} 0.03 \pm 0.00^{\mathrm{b}} 0.66 \pm 0.00^{\mathrm{a}} 24.6 \pm 2.7^{\mathrm{b}} \quad 0.54 \pm 0.01^{\mathrm{b}} 0.14 \pm 0.00^{\mathrm{a}} \quad 27.5 \pm 2.86^{\mathrm{b}} \quad 0.35$

T. triangulare Oven dried $20.77 \pm 0.36^{\mathrm{a}} 0.48 \pm 0.04^{\mathrm{a}} \quad 0.61 \pm 0.01^{\mathrm{a}} 0.98 \pm 0.14^{\mathrm{a}} \quad 38.6 \pm 7.2^{\mathrm{a}} \quad 0.61 \pm 0.06^{\mathrm{b}} \quad 0.54 \pm 0.00^{\mathrm{a}} \quad 62.6 \pm 7.82^{\mathrm{a}} \quad 3.81$

$(12.12 \pm 1.06)$ Sundried $\quad 12.97 \pm 0.13^{\mathrm{b}} 0.31 \pm 0.06^{\mathrm{b}} 0.42 \pm 0.07^{\mathrm{b}} \quad 0.77 \pm 0.19^{\mathrm{a}} \quad 35.6 \pm 4.9^{\mathrm{a}} \quad 6.83 \pm 0.85^{\mathrm{a}} \quad 0.29 \pm 0.06^{\mathrm{a}} \quad 57.2 \pm 6.26^{\mathrm{a}} \quad 2.41$

V. unguiculata Oven dried $18.45 \pm 0.06^{\mathrm{a}} 0.38 \pm 0.01^{\mathrm{a}} 0.72 \pm 0.11^{\mathrm{a}} 1.16 \pm 0.05^{\mathrm{a}} 32.6 \pm 1.4^{\mathrm{a}} \quad 3.09 \pm 0.04^{\mathrm{a}} \quad 0.57 \pm 0.04^{\mathrm{a}} \quad 57.0 \pm 1.71^{\mathrm{a}} \quad 3.47$

$(7.21 \pm 1.13)$ Sun-dried $11.97 \pm 0.00^{\mathrm{b}} 0.37 \pm 0.00^{\mathrm{a}} 0.61 \pm 0.00^{\mathrm{b}} 1.07 \pm 0.00^{\mathrm{b}} 30.6 \pm 1.3^{\mathrm{a}} \quad 1.86 \pm 0.00^{\mathrm{b}} 0.33 \pm 0.02^{\mathrm{b}} \quad 46.8 \pm 1.33^{\mathrm{b}} \quad 2.33$

${ }^{1}$ Data are presented as means of triplicate analyses $\pm \mathrm{SD}$; ND. not detected. Means with the same superscript letter in the same column for a single vegetable are not different at $\mathrm{P}>0.05$. FW. fresh weight. 
$20 \%$, respectively. Although lutein is not a provitamin A carotenoid, it has antioxidant properties linked to its conjugated double bond structure. The relative ratio of lutein and $\beta$-carotene, is fairly constant in leafy vegetables most of these leafy vegetables. Just like Zeaxanthin, lutein is important in the prevention of age related macular degeneration thus prevent age related blindness [30]. Zeaxanthin and $\beta$-cryptoxanthin concentrations were lower than lutein $(\mathrm{P}<0.05)$. Some carotenoid concentrations varied with respect to those previously reported [31-33], [34]. For instance M. oleifera was found to have $22.89 \pm 6.8$ $\mathrm{mg} / 100 \mathrm{gDW}$ of $\beta$-carotene by Lakshminarayana and others [32] as opposed to $39.86 \pm 2.32$ in the present study. These differences may be related to species, location, degree of maturity at harvest, cultivation, and postharvest handling practices [35]

\subsection{Effects of Processing}

Sun-drying, squeeze-washing and boiling, and a combination of boiling in kanwa and squeeze-washing, are traditionally practiced in most local communities in tropical Africa. Total carotenoids were lower in most of the processed samples compared with the unprocessed oven-drived samples.

Sun-drying is the cheapest and most accessible means of food preservation in developing countries, but considerable losses of provitamin A carotenoids occur. Samples that were sundried were the most affected with most of the species loosing between $10 \%$ and $20 \%$ carotenoids as indicated by Clydesdale and others [36]. However total carotenoid losses of up to $47 \%$ were observed for $M$. oleifera. Gomez [37] showed that drying conditions resulted in a decrease in the concentration of carotenoids in kale, amaranth, cowpea, and cassava leaves when compared with the unprocessed samples. During the sundrying process, photooxidation of both trans- and cis carotenoids takes place resulting into epoxidation and cleavage to apocarotenals before fragmentations into a series of low mass compounds thus losing their biological activities. From these findings we can infer that oven drying is a better processing technique for carotenoid retention in foods than sundrying. However, in developing countries, oven drying is not always feasible especially in rural area where electricity is either not available or expensive. Su$\mathrm{n}$-drying primarily affected $\beta$-carotene, $\alpha$-carotene, and lutein with a maximum of $73.5 \%$ loss of $\beta$-carotene in $G$. africanum. These results are consistent with those of Pesek and Warthesen [38] who showed that only $25 \%$ of $\alpha$-carotene but $75 \%$ of $\beta$ carotene were lost during drying as a result of photooxidation.

Total carotenoid losses due to boiling, boiling and squeeze-washing, and a combination of boiling in kanwa and squeeze-washing, were lower in the species studied with highest loss of $23.6 \%$ in H. cannabinus when kanwa was used in boiling before squeeze-washing. These losses are as a result of both boiling and leaching in the presence of a base (kanwa). Baloch and others [39] showed that boiling can cause carotenoid destruction of 5 to $15 \%$ due to the inactivation of enzymes like peroxidase and lypoxygenase. Leaching occurred during squeeze-washing and rinsing justifying the increased losses in the present study. Similar observations in both $\beta$ and $\alpha$-carotene were found by Mosha and others [22] when traditional processing techniques were applied to amaranth and sweet potato leaves. The concentration of $c i s$ isomer of $\beta$ carotene was usually the same but sometimes differed between the unprocessed and processed vegetables. Processing can increase the percentage of cis isomers in foods [39,40]. In raw foods, $\beta$-carotene is predominantly in the all-trans form, but with blanching, boiling, and exposure to light, isomerization to the cis form increases as most carotenoids are highly unsaturated [41]. The cis form is estimated to have only $38 \%-53 \%$ of the biological potency of the all-trans forms [42]. Losses in the $\alpha$-carotene in these samples were not as large as that of $\beta$-carotene. The alleged low retention values for-carotene can simply be due to the greater ease with which carotenoids of cooked or processed samples can be extracted compared with those of fresh foods. They might also be due to unaccounted moisture and soluble solid losses, which would concentrate and increase the provitamin A levels per unit weight of food. Rahman and others. [20] found 96 to 98 percent retention of $\beta$-carotene in two leafy vegetables. For most of the vegetables, no significant differences were observed between the samples boiled with or without kanwa and squeeze-washed (P > 0.05). The effect of boiling with or without kanwa on all the different carotenoids was minimized as the samples were finally oven-dried after these processes.

\subsection{Vitamin A Activity/Retinol Equivalent}

$\beta$-Carotene, 13-cis- $\beta$-carotene, 9-cis- $\beta$-carotene, $\alpha$-carotene and $\beta$-cryptoxanthin are the provitamin A carotenoids analysed in the leafy vegetables. Vitamin A or retinol is essentially one half of the -carotene molecule thus making $\beta$-carotene the principal source of vitamin A from these leafy vegetables. The vitamin A activity for these foods were between 1.05 in $P$. purpureum (Table 1) and $7.08 \mathrm{mg}$ per $100 \mathrm{~g}$ in M. oleifera (Table 2). Interestingly, most of the vegetables found abundant in the region had high retinol equivalent above $2.8 \mathrm{mg} / 100 \mathrm{gDW}$. These values are similar to values obtained from some of their counterparts commonly used in India (Rajyalakshmi and others [44]. The nutritional importance of the leafy vegetables rich in retinol equivalent need to be promoted within the communities to alleviate vitamin A deficiencies.

\section{Conclusions}

In conclusion, these tropical green leafy vegetables in 
unprocessed and processed forms have high levels of many carotenoids, notably $\beta$-carotene and lutein. These vegetables have also been shown to possess high retinol equivalents. Although household preparation and processing procedures, such as boiling and drying, help to liberate the carotenoids from their cellular matrix enabling them to be available for absorption, these processes lead to significant losses especially for $\beta$-carotene during sun-drying. Nonetheless, many of these vegetables are rich sources of carotenoids that should be promoted by nutritionists and public health workers in the African region to overcome vitamin A deficiencies and age related macular degeneration

\section{Acknowledgements}

This research was supported by the American government through a Fulbright grant to RAE and Hatch Wisconsin Agricultural Experiment Station WIS04975 to SAT. The authors thank Chris Davis and Sara Arscott for their assistance in the laboratory work.

\section{REFERENCES}

[1] R. A. Ejoh, A. N. Tanya and V. N. Djuikwo, C. M. Mbofung, "Effect of Processing and Preservation on the Iron and Vitamin A Levels of Some Species of Vernonia," Sciences des Aliments, Vol. 25, No. 3, 2005, pp. 189-192. doi:10.3166/sda.25.185-192

[2] FAO/WHO, "Workshop on Fruit and Vegetables for Hea1th. Fruit and Vegetables for Health," Report of a Joint FAO/WHO Workshop, Kobe, 1-3 September 2004.

[3] S. A. Tanumihardjo and Z. Yang, "Epidemiology of Health Effects," In: B. Caballero, L. Allen, A. Prentice, Eds., Encyclopedia of Human Nutrition, 2nd Edition, Elsevier Ltd., Oxford, 2005, pp. 339-345. doi:10.1016/B0-12-226694-3/00048-X

[4] M. Kimura and D. B. Rodriguez-Amaya, "Carotenoid Composition of Hydroponic Leafy Vegetables," Journal of Agricultural Food Chemistry, Vol. 51, No. 9, 2003, pp. 2603-2607. doi:10.1021/jf020539b

[5] P. R. G. De Oliveira and D. B. Rodriquez-Amaya, "Processed and Prepared Corn Products as Sources of Lutein and Zeaxanthin: Compositional Variation in the Food Chain," Journal of Food Science, Vol. 72, No. 1, 2007, pp. S79-S85. doi:10.1111/j.1750-3841.2006.00235.x

[6] D. S. McLauren and M. Frigg, "Practical Guide on Vitamin A in Health and Disease," "Sight and Life Manual, Sight and Life Publication, 2002, p. 172.

[7] S. A. Tanumihardjo, "Food-Based Approaches for EnsuRing Adequate Vitamin A Nutrition," Comprehensive Review of Food Science and Food Safety, Vol. 7, 2008, pp. 373-381.

[8] N. I. Krinsky, "Actions of Carotenoids in Biological Systems," Annual Review of Nutrition, Vol. 13, 1993, pp. 561-587. doi:10.1146/annurev.nu.13.070193.003021

[9] A. Rodriguez-Bernaldo de Quiros and H. S. Costa, "Ana- lysis of Carotenoids in Vegetable and Plasma Sam- ples," Journal of Food Composition and Analysis, Vol. 19, No. 2-3, 2006, pp. 97-111. doi:10.1016/i.jfca.2005.04.004

[10] Institute of Medicine, "Dietary Reference Intakes for Vitamin A, Vitamin K, Arsenic, Boron, Chromium, Copper, Iodine, Iron, Manganese, Molybdenum, Nickel, Silicon, Vanadium, and Zinc," National Academy Press, Washington, D.C., 2001, pp. 65-126.

[11] WHO, "Global Prevalence of Vitamin A Deficiency in Populations at Risk 1995-2005," WHO Global Database on Vitamin A Deficiency, 2010

http://whqlibdoc.who.int/publications/2009/97892415980 19 eng.pdf

[12] K. J. Yeum and R. M. Russell, "Carotenoid Bioavailability and Bioconversion," Annual Review of Nutrition, Vol. 22, 2002, pp. 483-504. doi:10.1146/annurev.nutr.22.010402.102834

[13] M. T. Ruel, "Can Food Based Strategies Help Reduce Vitamin A and Iron Deficiencies? A Review of Recent Evidence," International Food Policy Research Institute, Washington, D.C., 2001, p. 79.

[14] K. Tontisrin, G. Nantel and L. Bhattacharjee, "FoodBased Strategies to Meet the Challenges of Micronutrient Malnutrition in the Developing World," Proceedings of Nutrition Society, Vol. 61, No. 2, 2002, pp. 243-250. doi:10.1079/PNS2002155

[15] R. A. Ejoh, V. N. Djuikwo, I. Gouado and C. M. Mbofung, "Effect of the Method of Processing and Preservation on Some Quality Parameters of Three Non- Conventional Leafy Vegetables," Pakistan Journal of Nutrition, Vol. 6, No. 2, 2007, pp. 128-133. doi:10.3923/pjn.2007.128.133

[16] K. Judprasong, S. Charoenkiatkul, P. Sungpuag, K. Vasanachitt and Y. Nakjamanong," "Total and Soluble Oxalate Contents in Thai Vegetables, Cereal Grains and Legume Seeds and Their Changes after Cooking," Journal of Food Composition and Analysis, Vol. 19, No. 4, 2006, pp. 340-347. doi:10.1016/j.jfca.2005.04.002

[17] U. Kidmosea, R. Y. Yang, S. H. Thilstedc, L. P. Christensena and K. Brand. "Content of Carotenoids in Commonly Consumed Asian Vegetables and Stability and Extractability during Frying," Journal of Food Composition and Analysis, Vol. 19, No. 6-7, 2006, pp. 562-571. doi:10.1016/j.jfca.2006.01.011

[18] E. S. Tee and C. L. Lim, "Carotenoid Composition and Content of Malaysian Vegetables and Fruits by AOAC and HPLC Methods," Food Chemistry, Vol. 41, 1991, No. pp. 309-339.

[19] E. P. Wasantwisut, V. Sungpuag, U. Chavasit, S. J. Chittchang and T. Viriyapanich, "Identifying and Recommending Vitamin A Rich Foods in Northeast Thailand," In: E. Wasantwisut and G. A. Attig, Eds., Empowering Vitamin A Foods, Institute of Nutrition, Bangkok, 1995, pp. 69-90.

[20] M. M. Rahman, M. A. Wahed, D. Mahalanabis and R. B. Sack, "Preparing and Preserving Green Leafy Vegetables for Poor Communities in Bangladesh," In: E. Wasantwisut and G. A. Attig, Eds., Empowering Vitamin A Foods. In- 
stitute of Nutrition, Bangkok, 1995, pp. 61-68.

[21] F. Khachik, M. B. Goli, G. R. Beecher, J. Holden, W. R. Lusby, M. D. Tenorio and M. R. Barrera, "Effect of Food Pre- Paration on Qualitative and Quantitative Distribution of Major Carotenoid Constituents of Tomatoes and Several Green Vegetables," Journal of Agricultural Food Chemistry, Vol. 40, No. 3, 1992, pp. 390-398. doi:10.1021/if00015a006

[22] T. C. Mosha, R. D. Pace, S. Adeyeye, H. S. Laswai and K. Mtebe, "Effect of Traditional Processing Practices on the Content of Total Carotenoid, $\beta$-Carotene, $\alpha$-Carotene and Vitamin A Activity of Selected Tanzanian Vegetables," Plant Foods for Human Nutrition Vol. 50, No. 3, 1997, pp. 189-201. doi:10.1007/BF02436056

[23] M. A. Horvitz, P. W Simon and S. A. Tanumihardjo, "Lycopene and Beta-Carotene Are Bioavailable from Lycopene 'Red' Carrots in Humans," European Journal of Clinical Nutrition, Vol. 58, 2004, pp. 803-811. doi:10.1038/sj.ejen. 1601880

[24] J. A. Howe and S. A. Tanumihardjo, "Evaluation of Analyticcal Methods for Carotenoid Extraction from Biofortified Maize (Zea mays sp.)," Journal of Agricultural Food Chemistry, Vol. 54, No. 21, 2006, pp. 7992-7797. doi:10.1021/jf062256f

[25] J. C. Bauerfeind, "Carotenoids as Colorants and Vitamin A Precursors," Academic Press, Orlando, 1984, p. 883.

[26] WHO, "Control of Vitamin A Deficiency and Xerophthalmia,"World Health Organization, 1982.

[27] National Research Council, "Recommended Dietary Allowances," 10th Edition, National Academy Press, Washington, D.C., 1989.

[28] B. Kandlakunta, A. Rajendran and L. Thingnganing, "Carotene Content of Some Common (Cereals, Pulses, Vegetables, Spices and Condiments) and Unconventional Sources of Plant Origin," Food Chemistry, Vol. 106, No. 1, 2008, pp. 85-89. doi:10.1016/j.foodchem.2007.05.071

[29] F. X. Cunningham Jr., "Regulation of Carotenoid Synthesis and Accumulation in Plants," Pure and Applied Chemistry, Vol. 74, No. 8, 2002, pp. 1409-1417. doi: $10.1351 / \mathrm{pac} 200274081409$

[30] D. J. Hart and K. J. Scott, "Development and Evaluation of an HPLC Method for the Analysis of Carotenoids in Foods and the Measurement of the Carotenoid Content of Vegetables and Fruits Commonly Consumed in UK," Food Chemistry, Vol. 54, No. 1, 1995, pp. 101-111. doi:10.1016/0308-8146(95)92669-B

[31] A. J. Speech, S. Speek-Saichua and W. H. P. Schreurs, "Total Carotenoid and $\beta$-Carotene Contents of Thai Vegetables and the Effect of Processing," Food Chemistry, Vol. 27, No. 4, 1988, pp. 245-257. doi:10.1016/0308-8146(88)90010-6

[32] R. Lakshminarayana, M. Raju, T. P. Krishnakantha and V. Baskaran, "Determination of Major Carotenoids in a Few Indian Leafy Vegetables by High-Performance Liquid Chromatography," Journal of Agricultural. Food Chemistry, Vol. 53, No. 8, 2005, pp. 2838-2842. doi:10.1021/jf0481711
[33] Y. S. Cho, K. J. Yeum, C. Y. Chen, G. Beretta, G. Tang, N. I. Krinsky, S. Yoon, Y. C. Lee-Kim, J. Blumberg and R. M. Russell. "Phytonutrients Affecting Hydrophilic and Lipophilic Antioxidant Activities in Fruits, Vegetables and Legumes," Journal of Science of Food Agriculture, Vol. 87, No. 6, 2007, pp. 1096-1107. doi:10.1002/jsfa. 2817

[34] L. Ryan, O. O'Connell, L. O'Sullivan, S. A. Aherne and N. M. O'Brien, "Micellarisation of Carotenoids from Raw and Cooked Vegetables," Plant Foods for Human Nutrition, Vol. 63, No. 3, 2008, pp. 127-133. doi:10.1007/s11130-008-0081-0

[35] B. H. Chen and Y. Y. Chen, "Determination of Carotenoids and Chlorophylls in Water Convolvulus (Ipomea aquatica) by Liquid Chromatography," Food Chemistry Vol. 45, No. 2, 1992, pp. 129-134. doi:10.1016/0308-8146(92)90023-U

[36] F. M. Clydesdale, C.-T. Ho, C. Y. Lee, N. I. Mondy and R. L. Shewfelt, "The Effects of Postharvest Treatment and Chemical Interactions on the Bioavailability of Ascorbic Acid, thiamin, Vitamin A, Carotenoids, and Minerals," Critical Reviews in Food Science and Nutri- tion, Vol. 30, 1991, No. 6, pp. 599-638.

[37] M. I. Gomez, "Carotene content of Some Green Leafy Vegetables of Kenya and Effects of Dehydration and Storage on Carotene Retention," Journal of Plant Foods, Vol. 3, 1981, pp. 231-244.

[38] C. A. Pesek and J. J. Warthesen, "Photodegradation of Carotenoids in a Vegetable Juice System," Journal of Food Science, Vol. 52, No. 3, 1987, pp. 744-746. doi:10.1111/j.1365-2621.1987.tb06717.x

[39] A. K. Baloch, K. A. Buckle and R. A. Edwards, "Effect of Processing Variables on Quality of Dehydrated Carrot. II. Leaching Losses and Stability of Carrot during Dehydration and Storage," Journal of Food Technology, Vol. 12, No. 3, 1977, pp. 295-307. doi:10.1111/j.1365-2621.1977.tb00110.x

[40] R. Aman, A. Schieber and R. Carle, "Effects of Heating and Illumination on Trans-cis Isomerization and Degradation of $\beta$-Carotene and Lutein in Isolated Spinach Chloroplasts," Journal of Agriculture and Food Chemistry, Vol. 53, No. 24, 2005. pp. 9512-9518. doi:10.1021/jf050926w

[41] S. K. Thakkar, B. Maziya-Dixon, A. G. O. Dixon and M. L. Failla, "Carotene Micellarization during in Vitro Digestion and Uptake by Caco-2 Cells is Directly Proportional to $\beta$-Carotene Content in Different Genotypes of Cassava," Journal of Nutrition, Vol. 137, 2007, pp. 22292233.

[42] L. A. Chandler and S. J. Schwartz, "Isomerization and Losses of Trans $\beta$-Carotene in Sweet Potatoes as Affected by Processing Treatment," Journal of Agricultural Food Chemistry, Vol. 36, No. 1, 1988, pp. 129-133. doi:10.1021/jf00079a033

[43] J. P. Sweeney and A. C. Marsh, "Effect of Processing on Provitamin A in Vegetables," Journal of American Dietetics Association, Vol. 59, 1971, pp. 238-243.

[44] P. Rajyalakshmi, K. Venkatalaxmi, K. Venkatalakshma- 
mma, Y. Jyothsna, K. Balachandramanidevi and V. Suneetha, "Total Carotenoid and $\beta$-Carotene Contents of Forest Green Leafy Vegetables Consumed by Tribals of
South India," Plant Foods Human Nutrition, Vol. 56, No. 3, 2001, pp. 225-238. doi:10.1023/A:1011125232097 